\title{
Application of Slick Water with Low Surface Tension in Water-Blocking
}

\section{Damaging Gas Reservoirs}

\author{
ZHU Zhaopeng ${ }^{1, a}$ \\ ${ }^{1}$ PETRO CHINA JILIN OILFIELD COMPANY \\ azcdkp07@126.com
}

Keyword: slick water; low surface tension; water blocking damage; tight gas reservoirs

Abstract: The characteristics of WF gas oil in Jilin Oilfield are low porosity, low permeability, small pore-throat radius, and low formation pressure coefficient, causing that fracturing fluid flow back slowly, decreasing productivity. Laboratory test shows that water blocking damage is the major factor which restricts production of these gas oils. The water blocking damage is caused by fracturing fluid seepage among small pore-throats. The slick water fracturing fluid system is studied, which have low surface tension and high snit-swelling rate, decreasing the rate of water blocking damage to $20 \%$. This system is used in the fracture of Well C609. 15 hours later, gas breaks through. The flow back rate is up to $35 \%$ naturally. After gas lifting, the flow back rate is increased to $68 \%$, which is obviously higher than that rate in the similar wells using conventional fracturing fluid. The slick water fracturing fluid system is field applied on 16 wells. The natural flow back rate is from $16.5 \%$ up to $31.2 \%$. And the flow back rate is increased from $35 \%$ to $70.3 \%$ after gas lifting. It is proved that this system is obviously effective and hence shows promising application prospects.

\section{Introduction}

The technical trend of simulation of tight gas reservoir is mainly to improve transforming volume, increase the air supply radius, and reduce fracturing operation damage. Water sensitivity and water blocking damage are two key factors that influence the result of gas reservoirs simulation. Make the factors clear that damage the gas reservoirs, and then adopt several feasible countermeasures to reduce the damage.

WF gas oil in Jilin Oilfield is typical tight gas reservoir. It must be fractured to achieve industrial gas output. The average flow back rate is $16.5 \%$, relying on the formation energy after fracturing. The average flow back rate is increased to $35 \%$ after gas lifting. The fluid flow back rate in this block is so low that the initial production is little, or even there is no gas, no liquid, and no pressure in initial stage after fracturing. The wells' daily output would rise, and wellhead pressure would be down, when they are shut in for days (one month), or huff and puff nitrogen in these wells. To solve these problems, it is necessary to study the main damage of gas reservoir and then make feasible countermeasures.

\section{Reservoir characteristics and damage analysis}

\section{Poroperm characteristics}

The buried deepness of WF gas oil in Jilin Oilfield is from 2000 to 2900 meters. The porosity is from $5.8 \%$ to $6.7 \%$. The permeability is arranged from 0.021 to $0.067 \mathrm{mD}$, tested under the overburden pressure. The formation pressure coefficient is between 0.89 and 0.95 , tested on site. The production of the tight gas reservoir is so low, and the fluid flow back slowly after fracturing, mainly because of low porosity, low permeability, and low formation pressure coefficient. 


\section{Pore throat characteristics}

In order to analysis pore-throat characteristics of this reservoir intuitively, nanometer CT scanner is used. The results of Well C6 and Well C606 are shown in fig.1. Figure 1 depicts that there are a few microcracks, and the pore-throat radius are so small, ranging from 0.1 to 2 micrometers.

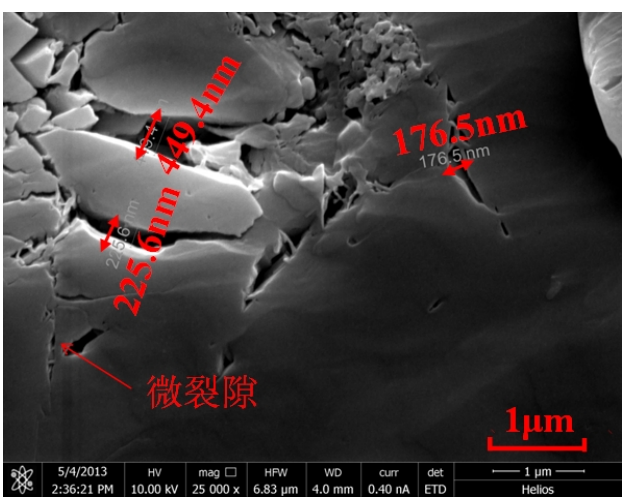

a) Well C6

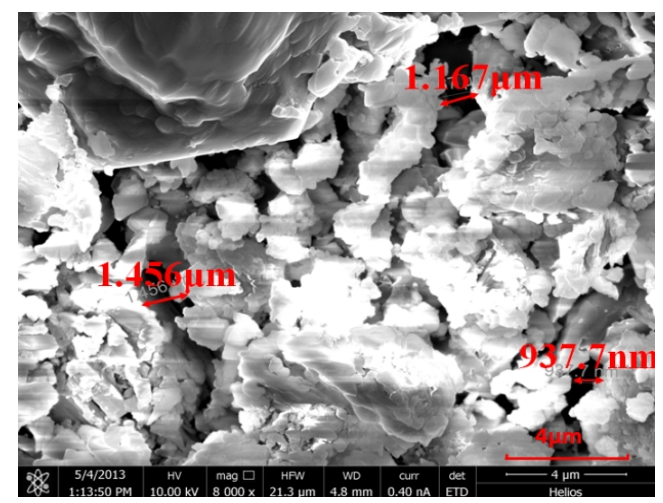

b) Well C606

Fig.1 Images of Nanometer CT scanner

From NMR T2 histogram of Well C6, we can see that the irreducible water saturation is up to $62.46 \%$, and the micropores account for $88 \%$ of the total pore space, making it easier for water blocking damage.

\section{Damage factors analysis}

According to SY/T 5358-2002 standard, make a test of sensitivity of WF gas field. The results are shown in Table 1. The main sensitivities of WF gas field are acid sensitivity (from weak to strong) and water sensitivity (from weak to strong medium). So select non-acid liquid to prevent from acid sensitivity. And select anti-swelling agent, or optimize mineral concentration of fracture fluid to against water sensitivity.

Table 1 sensitivity analysis

\begin{tabular}{|c|c|c|c|c|c|c|c|}
\hline $\begin{array}{l}\text { Well } \\
\text { Name }\end{array}$ & $\begin{array}{l}\text { interv } \\
\text { al }\end{array}$ & $\begin{array}{l}\text { form } \\
\text { ation }\end{array}$ & water sensitivity & velocity sensitivity & $\begin{array}{c}\text { acid } \\
\text { sensitivity }\end{array}$ & $\begin{array}{c}\text { alkali } \\
\text { sensitivity }\end{array}$ & $\begin{array}{c}\text { stress } \\
\text { sensitivity }\end{array}$ \\
\hline C6 & 2524 & $\begin{array}{l}\text { Shah } \\
\text { ezi }\end{array}$ & $\begin{array}{l}\text { weak medium, critical } \\
\text { mineral } \\
\text { concentration:3000mg/l }\end{array}$ & $\begin{array}{c}\text { weak, critical } \\
\text { velocity: } 3 \mathrm{~cm}^{3} / \mathrm{min}\end{array}$ & $\begin{array}{l}\text { strong } \\
\text { medium }\end{array}$ & $\begin{array}{l}\text { weak - weak } \\
\text { medium, } \\
\text { critical PH:10 }\end{array}$ & $\begin{array}{l}\text { weak } \\
\text { medium }\end{array}$ \\
\hline C11 & 2853 & $\begin{array}{l}\text { Huos } \\
\text { hiling }\end{array}$ & $\begin{array}{l}\text { strong medium, critical } \\
\text { mineral } \\
\text { concentration: } 3500 \mathrm{mg} / \mathrm{l}\end{array}$ & $\begin{array}{c}\text { weak, critical } \\
\text { velocity: } 2.5 \mathrm{~cm}^{3} / \mathrm{min}\end{array}$ & weak & $\begin{array}{l}\text { weak - weak } \\
\text { medium, } \\
\text { critical PH:10 }\end{array}$ & $\begin{array}{l}\text { weak } \\
\text { medium }\end{array}$ \\
\hline C603 & 2829 & $\begin{array}{l}\text { Huos } \\
\text { hiling }\end{array}$ & $\begin{array}{l}\text { weak critical mineral } \\
\text { concentration:3500mg/l }\end{array}$ & $\begin{array}{c}\text { weak medium, } \\
\text { critical } \\
\text { velocity: } 2.5 \mathrm{~cm}^{3} / \mathrm{min}\end{array}$ & strong & $\begin{array}{l}\text { weak - weak } \\
\text { medium, } \\
\text { critical PH:10 }\end{array}$ & $\begin{array}{l}\text { weak } \\
\text { medium }\end{array}$ \\
\hline
\end{tabular}

After simulated formation water pushed into six core samples of Well C603, the water locking damage rates of core sample effect from $67 \%$ to $97 \%$, averagely $82.7 \%$. 
On the basis of the experiment of core sensitivity and the experiment of water locking damage above, the reason why the fluid flow back rate is low, the initial production is little, or even there is no gas, no liquid, and no pressure in initial stage after fracturing is that capillary force caused by invasion fluid flooding in small pore-throats is so strong that formation pressure can't against the capillary force. Decrease surface tension of invasion fluid, increase contact angle to almost $90^{\circ}$, and then reduce capillary force, lessening water locking damage in tight gas reservoirs. Eventually, using low surface tension fracturing fluid is an effective way to reduce water locking damage.

\section{Performance evaluation}

\section{Conventional performance}

WF gas oil is typical tight gas reservoir, where there is brittle rock with high strength. The slick water fracturing fluid system brings forth high net pressure by means of injecting large displacement into the formation. Crack brittle formation, form seam network, and enlarge transforming volume, achieving the purpose of improving production. There is no insoluble residue in slick water. Through optimize formulation to lower water sensitivity and locking damage, it is enough to meet the demand that reduce reservoir damage. The resistance-reducing rate and anti-swelling rate for this system should be high, and the surface tension and the apparent viscosity should be low. The targets of this system used in WF gas field are shown in Table 2.

Table 2 targets of slick water fracturing fluid system

\begin{tabular}{c|c|c|c|c|c|c|c|c}
\hline $\begin{array}{c}\text { Target } \\
\text { name }\end{array}$ & $\begin{array}{c}\text { resistance-reducing } \\
\text { rate, } \%\end{array}$ & $\begin{array}{c}\text { anti-swelling } \\
\text { rate, } \%\end{array}$ & $\begin{array}{c}\text { surface } \\
\text { tension, } \\
\mathrm{mN} / \mathrm{m}\end{array}$ & $\begin{array}{c}\text { interfacial } \\
\text { tension, } \\
\mathrm{mN} / \mathrm{m}\end{array}$ & $\begin{array}{c}\text { contact } \\
\text { angle, }\end{array}$ & $\begin{array}{c}\text { apparent } \\
\text { viscosity, } \\
\mathrm{mPa} \bullet \mathrm{s}\end{array}$ & $\begin{array}{l}\text { core } \\
\text { permeability } \\
\text { damage rate, } \%\end{array}$ & $\begin{array}{l}\text { PH } \\
\text { Measured } \\
\text { data }\end{array}$ \\
\hline
\end{tabular}

\section{Water locking damage}

Detect gas permeability that different concentrations of surfactant are used to displace the tight core. From fig. 2 , the rate of water blocking damage is ranged from $80 \%$ without surfactant, to under $20 \%$, obviously effective reduced.

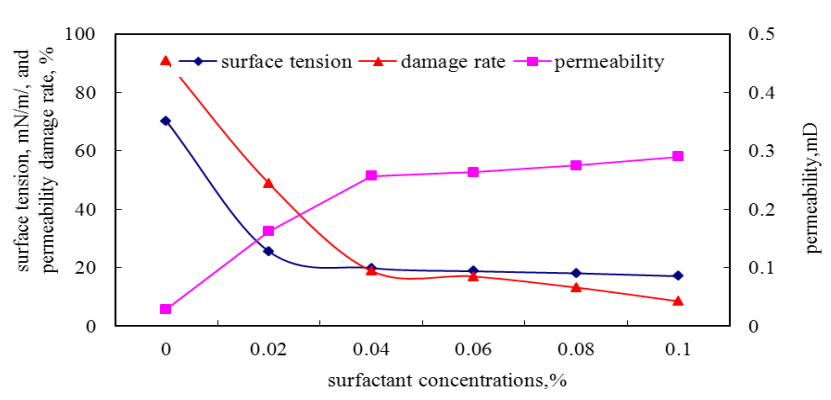

Fig.2 Relationship between concentrations of surfactant and rate of water blocking damage

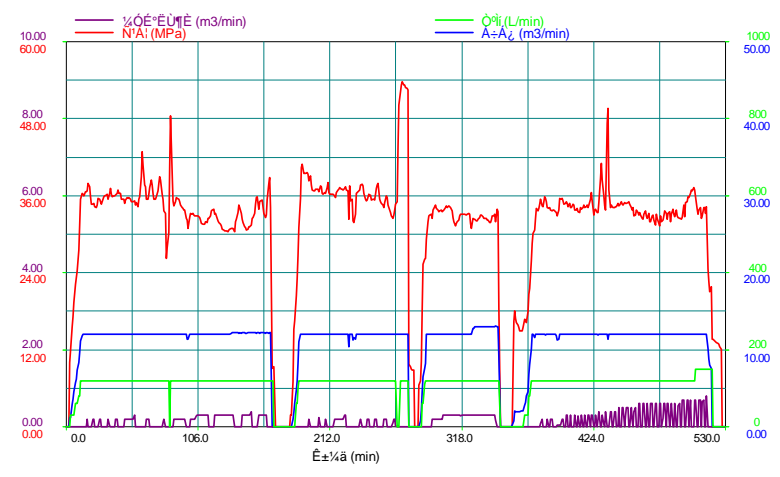

Fig.3 Fracture construction curve of Well C609

\section{Application effects}

Select Well C609 as representative of WF gas field. It is a vertical well developed. Its depth is 2838 meters. The porosity is $6.7 \%$. The permeability is $0.067 \mathrm{mD}$. The formation pressure coefficient is $0.89 \mathrm{MPa} / 100 \mathrm{~m}$. Its formation used is Huoshiling and Shahezi. In all, the 
characteristics of Well C609 are low porosity, low permeability, and tight reservoir. It is essential to apply the slick water fracturing fluid system studied, to transform the reservoir.

Inject slick water into Well C609 in the whole course of fracturing, and apply sand slug technique, in order to prevent sand plug. Separate layer fractures, and then gas test together. The displacement is $12 \mathrm{~m}^{3} / \mathrm{min}$. Inject $5548 \mathrm{~m}^{3}$ slick water into Well C609 totally. Three stages of $69 \mathrm{~m}^{3}$ sand are added. After fracturing fluid flow back 15 hours, gas breakthrough. The flow back rate is up to $35 \%$, relying on the formation energy. And then it is increased to $68 \%$ after gas lifting.

There are 15 wells applying this system. Gas breaks through after fracturing fluid flow back 5-33 hours. The average flow back rate is $31.2 \%$, relying on the formation energy after fracturing. The average flow back rate is increased to $70.3 \%$ after gas lifting. The results are effective obviously, reducing water locking damage and improving the flow back rate.

\section{Conclusion}

In the paper, conclusions are achieved as follows:

(1) The main reason why fracturing fluid flow back slowly, decreasing the productivity of WF gas field, is that water locking damage the formation after fracturing fluid flow into it.

(2) The surface tension of the slick water fracturing fluid system studied in this paper is so small that the water damage is reduced effectively.

(3) The system is applied on 16 wells. Gas breaks through quickly. The flow back rate is increased sharply. It is proved that this system is obviously effective and hence shows fairly good application prospects.

\section{Acknowledgements}

This work was financially supported by oil-gas engineering research institute in PETRO CHINA JILIN OILFIELD COMPANY.

\section{Reference}

[1] Crane Company Industrial Products Group. Flow of Fluids Through Valves, Fittings and Pipe[R]. Chicago Technical Paper No.410

[2] YANG Yongli. Study Water Locking Damage Mechanism and Water Unlocking of Low Permeability Reservoir [J]. Journal of Southwest Petroleum University(Science \& Technology Edition), 2013,35(3):137-141.

[3] QIU Zhengsong, PANG Peicheng, HUANG Weian, GAO Hongsong, LIU Junyi. Preparation and performance of anti-waterblock microemulsion for shale reservoirs [J], Acta petrolei sinica, 2013,34(2):334-339.

[4] ZHAO Zhongcong, LIU Tongyi, LIN Bo, et al. Development and assessment of anovel low-temperature breaker of clean fracturing fluid [J]. Journal of Yangtze University(Nat Sci Edit) Sci\&Eng, 2012,09(5):125-127.

[5] JIANG Guancheng, XU Weixing, LI Yingying, LI Ling. Technology of Fracturing Fluid with Friction-reducing Water Overseas and Its Reseach Progress[J]. Special Oil\&Gas Reservoirs, 2013, 20(1):1-6. 